\title{
O corpo feminino, frágil, malsão: um estudo do habitus de gênero dos militares combatentes do Exército Brasileiro
}

\author{
The female body, fragile, unhealthy: \\ a study of the gender habitus of military combatants
}

Rev. Bra. Est. Def. v. 2, no 1, jan./jun. 2015, p. 138-153

ISSN 2358-3932

\section{SUZANA MARLY DA COSTA MAGALHÃES* ANA LÍDIA DE ANDRADE***}

\section{1. iNTRODUÇÃO}

A problemática de gênero constitui-se como um dos aspectos mais destacados da sociedade contemporânea, tendo sido redimensionado, ultrapassando as oposições binárias entre os sexos no sentido de aceitar diversas identidades sexuais, o que era inconcebível para a sociedade tradicional, que prescrevia papéis sexuais fixos, com base nas diferenças biológicas. Atualmente, ao contrário, difundiu-se mais a convicção que as identidades sexuais são múltiplas, e construídas umas em relação às outras e a partir de atos performativos, que incluem falas e interações sociais em contextos específicos (Butler, 2003). Desse modo, dispostos em regime de oposição, superposição e complementaridade, supõe-se que as estruturas socioculturais de gênero se transformam ou permanecem relacionadas a fatores religiosos, econômicos, políticos e educacionais.

Neste sentido, considera-se pertinente abordar o fenômeno de construção de gênero no Exército Brasileiro (EB), que sempre foi uma corporação profissional de caráter quase exclusivamente masculino, onde as mulheres estavam inseridas recentemente somente em alguns segmentos de caráter técnico, de suporte ao combate, mas que, a partir da Lei $n^{\circ} 12705$, de 08 de agosto de 2012, foi obrigado a aceitar mulheres na linha bélica,

\footnotetext{
* Doutora em Estudos Ibéricos e Latino-americanos (Université de Paris III) e Pós-Doutora em Estudos sobre Militares (FGV). Oficial do Quadro Complementar de Oficiais do Exército Brasileiro. E-mail: suzanamarlyc@hotmail.com.

** Graduada em Ciências Sociais (UFRJ). E-mail: analidiadeandrade@gmail.com.
} 
como combatentes, assim como a Marinha e a Aeronáutica, em condições e níveis de acesso a serem determinados pela própria Força Terrestre.

Nesta perspectiva, para além do estudo das condições de infraestrutura do Exército, relativas aos aspectos materiais e normativos da instituição militar, pensa-se que é importante caracterizar as visões de mundo e a sensibilidade dos militares em relação às questões de gênero, para antecipar um rol de problemas que podem surgir das políticas de inserção de mulheres.

Os estudos sobre a inserção das mulheres nas Forças Armadas e auxiliares no país são ainda relativamente incipientes, até pela extrema dificuldade de acesso às instituições militares para a realização de trabalhos mais reveladores, de cunho qualitativo, etnográfico, destacando-se a tese de doutoramento Takahashi (2002), sobre a inserção das mulheres na Academia da Força Aérea (AFA), e a obra de Soares e Musumeci (2005).

Este estudo baseou-se nas categorias de habitus e de campo, de Bourdieu (2011), para situar as percepções de gênero no âmbito da instituição militar. Depreende-se aqui o habitus como uma instância correspondente à dimensão subjetiva da vida social, que se consubstancia em um conjunto de maneiras de sentir, pensar e agir dos indivíduos, manifestando-se no gestual, nos hábitos e gostos, que é transmitido por meio de processos de socialização. $\mathrm{O}$ habitus inclui também as atitudes, que se concretizam em comportamentos observáveis recorrentes, tais como as opiniões e os atos manifestos.

O habitus brota de uma estrutura social ou campo, que funciona como um espaço social permeado de coalizões e conflitos, sob o influxo de transformações de cunho econômico e social. A relação entre habitus e campo é de influência recíproca, uma vez que o habitus repercute sobre o campo, reproduzindo-o e reestruturando-o em conformidade com novas lógicas.

Deste modo, o habitus de gênero dos oficiais do EB, que estrutura as instâncias do masculino e do feminino, vincula-se à relação dos militares com o mundo e à sua compreensão da atividade militar e do papel do Exército na sociedade brasileira.

Além das categorias de Bourdieu (2011), foi utilizado o enfoque de Foucault (1988) relacionado com a constituição de um discurso médico sobre o corpo, que se relaciona com as instâncias de poder e saber, e de Goffman (2001) sobre as instituições totais. Foram incluídas ainda as contribuições de alguns estudos empíricos sobre a inserção da mulher nas forças auxiliares, como a polícia, e uma literatura que caracteriza os principais vetores 
do pensamento doutrinário vigente no Exército Brasileiro atualmente, além de um estudo de campo próprio.

Nesta perspectiva, foi, então, caracterizado o habitus dos militares em relação à divisão sexual em gênero, referente às atividades propriamente militares, tendo sido enfocadas estritamente as opiniões de oficiais combatentes sobre o desempenho das mulheres em atividades esportivas e de campanha e sobre as condições adequadas de inserção nos quadros, armas e serviços da linha bélica, destinados ao combate, no âmbito da Força Terrestre.

Para tal, o presente estudo realizou entrevistas não estruturadas com 25 oficiais de diferentes quadros, armas e serviços da linha bélica, instrutores de um estabelecimento de ensino subordinado ao Departamento de Educação e Cultura do Exército (DECEx) ao longo do ano de 2012, no local de trabalho destes militares, por meio de grupos focais de dois até cinco militares.

Este trabalho analisou os aspectos mais destacados da vida e da carreira militar da linha bélica, relacionados com a identidade profissional e com as estruturas de poder vigentes na instituição militar: as atividades de educação física e de treinamento militar; o estatuto das mulheres no âmbito das armas de combate e de apoio; e as implicações de gênero das diversas concepções doutrinárias de emprego militar.

\section{AS INADEQUAÇÕES E INSUFICIÊNCIAS DA MULHER PARA O COMBATE: O TREINAMENTO FÍSICO MILITAR (TFM) E AS ATIVIDADES DE CAMPANHA}

Anicialmente, constatou-se que o habitus de gênero desses militares se baseia principalmente em configurações discursivas hauridas da ciência positiva, exprimindo determinados dispositivos da sexualidade vigentes há muito tempo na instituição militar. São concepções enraizadas em tradições intelectuais positivistas que foram estruturadas no final do século XIX, sob a égide do pensamento e da ação política de Benjamin Constant e de outros republicanos.

Depreendem-se aqui configurações discursivas como uma variedade de discursos que circulam nos interstícios das instituições, manifestadas enquanto vontade de saber e de poder. Deste modo, nas instituições militares, proliferam definições da essência da atividade militar relacionadas ao gênero, que disseminam, de modo informal e formal, por meio de um regime de enunciados, um conjunto de prescrições sobre o que as mulheres 
podem e devem fazer nas instituições militares.

Essas configurações discursivas atuam mais efetivamente nas instituições militares do que nas civis, devido à natureza repressiva da instituição militar, que se caracteriza precisamente por ser uma instituição total, no dizer de Goffmann (2001), estabelecendo mecanismos de controle em um espaço social hermético, fechado sobre si mesmo.

As configurações discursivas, tecidas em uma trama de relações de poder-saber estabelecidas na historicidade, nutrem e embasam os habitus de gênero dos militares brasileiros, amalgamando determinadas formas de sentir e de perceber o corpo masculino e feminino, de gerir as atividades militares de homens e mulheres, de portar o uniforme e de exigir a adequação ao protocolo de apresentação pessoal.

Nessa perspectiva, percebe-se o reflexo, no seio da instituição militar, de um habitus que reduz o corpo feminino à responsabilidade biológica-moral da sexualidade e da reprodução, que tem estabelecido para o sexo feminino modelos complementares em relação ao modelo masculino de soldado: a mãe, com a sua imagem em negativo da mulher nervosa, histérica.

Deste modo, a feminilidade é definida, no habitus desses instrutores, por meio dos artifícios retóricos da naturalização do corpo. Este é percebido como potencialmente doente, porque atingido por moléstias essencialmente femininas. Ele é, portanto, compreendido como um ente "saturado de sexualidade, [sendo] integrado, sob o efeito de uma patologia que lhe seria intrínseca, ao campo das práticas médicas." (Foucault, 1988: 115).

$\mathrm{Na}$ verdade, o que se constata na fala desses instrutores é a determinação das mulheres a partir do sexo/gênero, o que "permitiu agrupar" elementos anatômicos, funções psicológicas, condutas, sensações e prazeres, no sentido de construir um ente como princípio causal de um modo de ser e das doenças, percebido "como anatomia e falha, como função e latência, como instinto e sentido." (idem: 168).

Assim sendo, no âmbito das instituições militares, sob o influxo de uma preocupação crescente com a sexualidade/gênero, difundiu-se a concepção de uma feminilidade entendida como desvio ou deficiência imanente, de uma mulher que é constantemente ameaçada de moléstias por causa das partes de seu organismo que se remetem diretamente à feminilidade - as vias genitais.

A essência da feminilidade repousaria claramente sobre a região genital, e é esta, precisamente, a que a indispõe ao combate, como se constata na alusão recorrente à infecção urinária: “[e] aí muitas vezes vai ter infecção 
urinária. Vai ter problema.” (Oficial intermediário de Infantaria).

Nessa perspectiva, quando abordam as atividades físicas, os militares evidenciam um habitus no qual o gênero se constitui como um "poder causal inesgotável e polimorfo" (Foucault, 1988), que considera exclusivamente os aspectos imanentes e universais relacionados à feminilidade e à masculinidade, em detrimento de outras dimensões da pessoa que se imbricam à sociedade ou à cultura.

Isto acontece também porque, baseando-se nos referenciais positivos provenientes da Educação Física, Biologia e Medicina, os militares estabelecem padrões fixos de desempenho físico que hierarquizam homens e mulheres. Apenas aparentemente, o TFM é percebido como uma atividade rigorosamente equalizadora, idêntica para os dois sexos. Este deve ser realizado segundo um modelo estático, sem nenhuma diferenciação de práticas desportivas, o que, segundo o modelo atualmente em vigor, é orientado exclusivamente pelas características biológicas masculinas:

Oficial intermediário de Infantaria: O objetivo do TFM é colocar você numa situação física em que você tenha condição de executar a atividade militar sem prejudicar a saúde. Então, se ela vai desenvolver a mesma atividade militar do homem, ela tem que carregar o mesmo peso para preservar a saúde dela, ela vai ter que ter um treinamento físico militar parecido.

Mesmo quando confrontados com o aparente contrassenso de submeter organismos diferentes a treinamentos idênticos, uma vez que sempre partem do princípio que homens e mulheres se distinguem precisamente em função de aspectos orgânicos, esses militares rejeitam a implantação de um modelo diferenciado de TFM para homens e mulheres. Na verdade, a defesa da isonomia oculta a valorização exclusiva do corpo masculino e a negação da alteridade e especificidade do corpo feminino.

Além disso, os entrevistados se recusam a admitir as implicações das premissas de que partem, de que há corpos absolutamente distintos, o que demandaria um treinamento diferenciado, pois não aceitam que as mulheres possam atingir, enquanto indivíduos biológicos diferenciados dos homens, quaisquer resultados aperfeiçoados a partir da realização de atividades físicas de natureza compensatória.

Além da defesa de um TFM de modelo masculinizante, a inserção das mulheres nas atividades militares, que definem propriamente a profissão militar, é compreendida como um verdadeiro problema operacional, que compromete as possibilidades de cumprimento da missão constitucional, 
ameaçando a eficiência na execução das operações militares. Essa inserção inviabilizaria, inclusive, o exercício de algumas funções de combate que definem atualmente a instituição Exército, como a Infantaria e a Cavalaria.

A perda de capacidade operacional é intensificada ainda devido ao comprometimento do exercício da liderança, que se baseia na execução exemplar das atividades militares, tais como o TFM e as atividades físicas, e que seria incompatível com as condições físicas da mulher:

Oficial intermediário de Infantaria: A gente trabalha, por exemplo, com um poder de referência, que é o exemplo. A mulher, ela vai conseguir em todas as atividades peculiares da vida militar de Infantaria dar o exemplo para o soldado pra ter base de poder de referência? Então tem algumas limitações que ela teria para o exercício no efetivo com homens numa situação de combate.

Entrevistador: Isso vai gerar diferença de tratamento pelos outros militares, será?

Oficial intermediário de Infantaria 2: Principalmente, pelo subordinado.

Entrevistador: Vai afetar a liderança?

Oficial intermediário de Infantaria 2: Com certeza.

Os instrutores, de maneira geral, aceitam mais facilmente o exercício da autoridade da chefia e liderança no âmbito do trabalho administrativo, resistindo a aceitar a chefia/liderança relacionada à atividade operacional, um aspecto que se torna problemático na aceitação da inserção das mulheres na linha bélica. Neste caso, há quem legitime este ponto de vista a partir de características sexistas da própria cultura brasileira:

Oficial intermediário de Infantaria: Na situação da mulher, o que seria uma situação de comando, combatente, comandando soldados aí envolve outras coisas que aí, com certeza, eu imagino que vá dar diferença entre homem e mulher. Uma diferença cultural que daí não é do Exército, né? É do brasileiro.

A rejeição ao comando feminino em atividades operacionais é tão extremada que se considera preferível aceitar homens com graves limitações físicas e psicológicas do que uma mulher com desempenho físico excepcional, que, em tese, poderia emancipa-la da condição de mulher:

Entrevistador: Quando a gente vê um homem gordo pra caramba na Infantaria, é ruim. Ele não consegue comandar o pelotão dele.

Oficial intermediário de Infantaria 1: Tem gordo que consegue comandar.

Entrevistador: Por exemplo, o cara gago. O cara gago é brabo.

Oficial intermediário de Infantaria 1: Tem mais dificuldade.

Entrevistador: Uma atleta olímpica, ela consegue fazer qualquer coisa na Infantaria. Uma mulher, uma atleta olímpica, uma mulher dessa não tem nem menstruação.

Oficial intermediário de Infantaria 1: Uma atleta olímpica, na Infantaria, ela 
RBED, v. 2, no 1, jan./jun. 2015

poderia até correr mais do que eu. Ela poderia até atirar melhor do que eu. Mas, no combate, nós somos levados a situações em que o fato dela ser mulher vai causar um prejuízo muito grande. Quer dizer... guerra na selva. Pô, na guerra na selva, nós estamos em ambiente úmido, molhado, o tempo todo. Dependendo da situação, você não vai tomar banho, não vai trocar de roupa.

Os militares expressam ainda o temor que essas clivagens de gênero, que são estáticas e unívocas, separando de modo estanque o feminino e o masculino, ameacem as estruturas fundamentais da instituição militar, que são a hierarquia e a disciplina, uma vez que a mulher não conseguiria impor a sua autoridade devido à sua incapacidade física.

Estes aspectos serão corroborados a seguir, na análise que demonstra a instituição de tetos de vidro para conter o nível de inserção das mulheres em patamares que não ameacem significativamente o poder militar masculino.

\section{A EXCLUSÃO DA MULHER NAS ARMAS DE COMBATE: A INSTITUIÇÃO DOS TETOS DE VIDRO DE GÊNERO}

A maior parte dos militares entrevistados exprime claramente a recusa de inserir a mulher nas chamadas armas de combate, a Infantaria e a Cavalaria, baseando-se, precisamente, na incapacidade física alegada anteriormente:

Oficial intermediário de Infantaria 1: Eu falo na Infantaria, porque o objetivo da Infantaria é o objetivo de combate, o corpo a corpo (....) então, se colocar uma mulher lá... você pode colocar a mulher pra sair no jornal (....) mas, taticamente, não é, é melhor você ter no combate um homem do que uma mulher. Uma questão fisiológica, não é porque a mulher é inferior.

Oficial subalterno de Intendência: Tirando a Infantaria e a Cavalaria, que são atividades bem na linha de frente, as outras, eu acredito que poderiam entrar em todas as áreas.

Essa opinião é majoritária dentre os entrevistados, contrapondo-se a uma minoria, que não estabelece limitações estruturais nem temporais para a inserção da mulher como combatente:

Oficial intermediário de Intendência: Tudo depende da adequação. Até dá pra entrar, no caso de todas as outras armas, daria tranquilamente. Porque a atividade talvez venha a ser compatível com o que pode, então poderia tratar tudo de uma vez, adequando todas as instalações, preparando tudo, o quadro de instrutores... Não vejo problema nenhum.

Mas, para muitos, o próprio processo de inserção teria que ser gradual, 
para diminuir o impacto na instituição militar. Constata-se aqui que a existência de um habitus de gênero de caráter médico, na instituição militar, relaciona-se às estruturas de poder da instituição militar - ao campo militar - onde é atribuído um maior capital simbólico, no dizer de Bourdieu $(2011)^{1}$, às duas armas de combate, Infantaria e Cavalaria, a que se segue a Artilharia, que conseguem atingir os mais altos postos de comando, a saber, de general de Brigada, Divisão e de Exército, sendo que as duas primeiras detêm o maior número de vagas.

Desse modo, as mulheres são aceitas somente nos quadros, armas e serviços de caráter não operacional, que detêm menor poder institucional. Esse ponto de vista foi consensual ao ponto de ter sido institucionalizado pelo Exército, que inseriu as mulheres somente na Logística (Material Bélico e Intendência), que realiza o apoio ao combate.

Ora, convém lembrar que é o acesso privilegiado das armas de combate aos altos postos de comando que determina a sua primazia na determinação dos rumos da instituição, das políticas da Força Terrestre, em detrimento dos quadros, armas e serviços de apoio, como Comunicações, Intendência e Material Bélico. Nesse sentido, o habitus de gênero dos instrutores entrevistados manifesta a situação política diferenciada das armas, quadros e serviços da linha bélica, que é inseparável "das localizações estratégicas, dos lugares a defender e conquistar em um campo de lutas” (Bourdieu, 2011: 45) no interior de um campo, a partir do qual é estabelecido para as mulheres um lugar subalterno na instituição militar.

A situação de hegemonia das armas de combate, às quais se junta a Artilharia, foi dominante a partir da constituição do Exército Brasileiro moderno, que projetou gradualmente o ideal do tarimbeiro, a partir de meados do século XIX. Daqui se origina o ponto de vista em que se identifica a profissão militar estritamente à atividade física e ao treinamento para o combate, menosprezando-se a preparação técnica e a formação intelectual como algo inferior, ou mesmo incompatível com a vocação militar.

Nesse contexto, as atividades mais típicas das armas de combate são consideradas a referência mais importante da instituição militar, a que define melhor a sua natureza. Nesse sentido, a educação física, o pentatlo militar, a marcha para o combate, o exercício de tiro, os exercícios de terreno são, então, considerados como as atividades mais relevantes da vida militar, em detrimento das atividades de preparação técnico-doutrinária.

Nessa perspectiva, é negada às mulheres, então assimiladas ao ator institucional não hegemônico do campo militar, a possibilidade da posse de 
bens culturais valorizados institucionalmente: o preparo físico adequado para o desempenho das atividades operacionais. A razão dessa recusa consiste no fato que a distribuição ampla do bem cultural ameaçaria a distinção dos militares das armas de combate.

O habitus de gênero dos instrutores, estruturado no seio das instituições militares, a partir das clivagens do campo militar, vincula-se também ao regime de gênero de raízes patriarcais, que ainda predomina na sociedade brasileira. Esse regime de gêneros se manifesta, por exemplo, na feminização das categorias profissionais situadas nos patamares inferiores da pirâmide ocupacional, em cargos e funções mais subalternas. Esta limitação no acesso se combina com o chamado teto de vidro, que consiste em limitações estruturais postas à inserção das mulheres em determinados cargos, funções ou campos da atividade profissional (Dantas, 2012). É interessante assinalar que o teto de vidro, para as mulheres, é inseparável de um nível de controle mais restrito "de seus próprios assuntos, de sua própria vida, de seu destino (....), de sua habilidade e competência para produzir, criar e gerir". (Melo, 2012: 346)

Neste sentido, o teto de vidro evidencia os aspectos constritivos do contexto social à concretização plena dos ideais democráticos e das políticas públicas daí decorrentes, apesar das pressões objetivas do mundo do trabalho. ${ }^{2}$ No caso, o represamento das mulheres na Logística seria uma manifestação de um teto de vidro incontornável e limitante para as suas possibilidades futuras de empoderamento no âmbito da Força Terrestre.

No item que se segue, foi nuançado o paradigma da exclusão das mulheres das armas de combate, ponderando-se o horizonte da doutrina militar e as diversas formas de emprego militar, como aspectos que influenciam consideravelmente o habitus de gênero dos militares da linha bélica.

\section{A REJEIÇÃO À INSERÇÃO DA MULHER NA LINHA BÉLICA E O ARCAÍSMO DOUTRINÁRIO}

A construção de um habitus de gênero sobre a mulher no âmbito de um saber médico e sua assimilação às armas, quadros e serviços técnicos que desfrutam de menor capital simbólico dentro da instituição manifesta ainda a face preocupante de um arcaísmo doutrinário que se recusa a pensar o exército contemporâneo. Nesse caso, o regime de gêneros se entrelaça a uma compreensão da atividade militar que é redutora e anacrônica, que rejeita, de modo inconsciente, as novas hipóteses de emprego, que definem 
melhor a instituição militar atualmente, quando considera somente as situações de combate convencional para avaliar a pertinência da inserção das mulheres.

Sobre o novo paradigma militar, das novas hipóteses de emprego, pode-se descrevê-lo, segundo Miranda (2013: 66), como uma forma de confronto com oponentes que podem ser "uma organização terrorista ou criminosa, um grupo guerrilheiro ou uma facção desertora de uma força armada, com ou sem apoio de Estados.”

Além disso, as novas hipóteses de emprego exigem uma forma de atuação da Força Terrestre em ambiente multinacional, em operações conjuntas e combinadas e interagências, que exijam o apoio das instituições políticas e da população civil, a ser obtido por meio da política e da mídia, pois se luta "não mais para ganhar batalhas, mas para conquistar corações e mentes, ou, em última instância, para manter o apoio político nacional e internacional ao governo que decidiu empregar as tropas, e para deslegitimar o oponente." (id. ibid.).

As novas hipóteses de emprego incluem também as operações de segurança pública e as operações de Garantia da Lei e da Ordem (GLO), que não podem ser reduzidas ou igualadas ao combate convencional. A guerra convencional continua a ser referência principal para a atividade militar, apesar do fato que o último conflito armado deste tipo em que atuou o Exército Brasileiro foi há quase 70 anos, na Segunda Guerra Mundial (1938-1945). Ora, as novas hipóteses de emprego são mais permeáveis à presença feminina por enfatizarem mais os habilidades de negociação e de tomada de decisão do que a força física, necessitando mais de um contingente de mulheres para se relacionar com a população civil, com a mídia e com as instituições militares, onde há também o segmento feminino.

O arcaísmo doutrinário como um obstáculo à difusão de um habitus de gênero mais favorável à inserção plena da mulher na linha bélica não é exclusivo da Força Terrestre, e reproduz aspectos típicos do processo de inserção da mulher nas polícias militares. Lá se verifica que a rejeição à inserção da mulher é associada à defesa acrítica, equivocada, de uma forma de atuação policial que tem sido contestada atualmente no contex to do estado democrático de direito. Nesse contexto, a polícia é instada a realizar algo mais do que simples ações repressivas. Mesmo assim, são depreciadas as atividades preventivas ou investigativas, que são mais associadas às mulheres do que aos homens (Musumeci, 2005).

Essa rejeição da mulher nas atividades de policiamento de rua pode 
ter sido favorecida pelo próprio modelo de inserção feminina utilizado no país, uma vez que foi gradual e com pequenos efetivos. As mulheres foram introduzidas nas atividades preventivas, que não representam os aspectos fundamentais associados à atividade policial, pois são caracterizadas pelo caráter educativo e pelo uso de estratégias de negociação e persuasão (Soares, 2005).

Desse modo, as mulheres teriam ocupado mais os cargos e funções relacionados ao policiamento de trânsito, policiamento ostensivo de terminais rodoviários, ferroviários e aeroviários ou às atividades burocráticas. Nessa perspectiva, a entrada das mulheres teria sido dificultada pelo obsoletismo doutrinário da corporação policial, uma vez que "o ingresso das mulheres, vale insistir, não foi acompanhado de nenhuma mudança substancial neste conceito de policiamento ou nas noções dominantes sobre o papel das polícias na previsão de segurança pública.” (Musumeci, 2005: 83).

Deste modo, o obsoletismo doutrinário difundido na Polícia Militar engendrou a polarização entre as atividades burocráticas e de perícia, consideradas como o polo intelectual, e feminino, e inscritas na esfera privada (da casa) e a esfera pública (da rua), que, na acepção de de da Matta (1988), é depreendida como um espaço de impessoalidade e de violência, que é mais associado aos homens.

Ou seja, à semelhança da polícia militar, o EB rejeita a inserção plena das mulheres em todas as atividades militares, tendo como base a defesa de formas mais datadas de atuação militar vinculadas à guerra convencional, represando as mulheres nas atividades técnicas, do suporte ao combate, e à logística.

Certamente, este apego ao modelo de guerra convencional deve-se à ausência da participação do país em guerras no último meio século. De fato, o nível tecnológico dos equipamentos militares, a burocratização e a ausência de guerras são fatores que dificultam que os militares elaborem outras concepções e práticas de ação militar. Eles influenciam fortemente uma cultura militar hegemônica no corpo de tropa, uma vez que as novas hipóteses de emprego, relacionadas à não-guerra e à guerra não convencional, impactam atualmente contingentes ainda muito restritos da Força Terrestre. Estes não são suficientes para gerar arejamento doutrinário no que concerne à compreensão da instituição militar e de sua missão constitucional no mundo contemporâneo, que é mais permeável à aceitação das mulheres como combatentes (Visacro, 2009). 


\section{CONCLUSÃO}

Constatou-se, na fala dos instrutores militares entrevistados, a presença recorrente de um discurso médico positivista, baseado nas ciências biológicas, que expressa uma concepção da feminilidade e do corpo da mulher determinada por aspectos biológicos imanentes. Nessa perspectiva, o corpo feminino é reduzido às suas funções de reprodução e cuidado, que são consideradas incompatíveis com o combate, que exige a enfrentamento de condições adversas, de que apenas os homens são considerados capazes.

A ideia de inadequação do corpo feminino ao combate, evidenciada no habitus de gênero dos instrutores, deve-se à presença, no âmbito da instituição militar, de um regime específico de sexualidade/gênero, que se relaciona também com concepções hegemônicas na sociedade brasileira contemporânea, enraizadas nas matrizes ideológicas da família patriarcal (Nogueira, 2004). Nessa perspectiva, a própria identidade do combatente e da instituição militar como um todo é ameaçada pela flexibilização de valores de desempenho físico e militar, que trabalha no sentido de incorporar as especificidades do corpo feminino.

O regime de gêneros, construído em torno aos diversos tipos de habitus de gênero e às configurações discursivas que circulam na instituição militar, relaciona-se também à preocupação com a manutenção e incremento de eficiência operacional, vinculada à defesa de um modelo de atividade militar baseado na força física e na guerra convencional, que rejeitou historicamente a presença das mulheres, enquanto as novas hipóteses de emprego seriam mais permeáveis à inserção das mulheres por enfatizar mais as habilidades de negociação e a capacidade de tomada de decisão.

Deste modo, conclui-se que, nas instituições militares, opõe-se o corpo feminino, frágil, medicalizado, ao corpo masculino, dotado de força e resistência, consubstanciando um habitus de rejeição ao corpo feminino e à sua inserção plena no espaço da caserna. 


\section{NOTAS}

1. O campo social produz práticas sociais e textos, que funcionam como um eixo gerador de outros textos e práticas sociais. Nessa perspectiva, é a posse, pelo indivíduo, destas práticas e textos, que consistem no que Bourdieu (2011) chama de capital cultural, ancorado no campo de forças sociais em que se situa o indivíduo, que estabelece as possibilidades concretas de ação social, no sentido da obtenção de posições de poder e prestígio.

2. "Com a evolução dos componentes eletrônicos, surge a necessidade argumentada das empresas de substituir a mão de obra masculina pela feminina por estas apresentarem maior habilidade manual, maior capacidade de trabalho delicado e minucioso e mais paciência para trabalharem com pequenas peças de microchips e outros componentes." (Melo, 2012: 351). 
O CORPO FEMININO, FRÁGIL, MALSÃO: UM ESTUDO DO HABITUS DE GÊNERO DOS MILITARES COMBATENTES DO EXÉRCITO BRASILEIRO

\section{RESUMO}

Caracterizou-se, por meio de entrevistas não estruturadas, o habitus de gênero dos militares combatentes no Exército Brasileiro. Neste sentido, o presente estudo realizou entrevistas abertas com 25 oficiais de diferentes quadros, armas e serviços da linha bélica, instrutores de um Estabelecimento de Ensino do Departamento de Educação e Cultura do Exército (DECEx), enfocando os aspectos relacionados com o desempenho das atividades esportivas e de campanha por mulheres e homens nas instituições militares, o estatuto das mulheres na estrutura de poder militar e as relações entre gênero e doutrina militar. Constatou-se a presença de um discurso médico positivista, que reduz o corpo feminino às suas funções socialmente estabelecidas de reprodução e cuidado e, portanto, considerando-o incompatível com o combate. Deste modo, os aspectos femininos são sempre interpretados a partir de indícios sugestivos de fragilidade física, que se opõem ao valor da rusticidade, central na profissão militar, de suportar condições físicas e materiais hostis, que é percebido como um atributo propriamente masculino.

Palavras-chave: inserção feminina, mulheres, gênero, linha de frente.

\section{ABSTRACT}

It is characterized through of unstructured interviews, the gender habitus of military combatants in the Brazilian Army. In this sense, this study conducted interviews with 25 officers from different frames, arms, and arms-line services, instructors of a Department of Education and Culture of Army (DECA), focusing on aspects related to the performance of activities sports and campaign by women and men in military institutions, the status of women in the military power structure and the relationship between gender and military doctrine. It was found the presence of a positivist medical discourse that reduces the female body to its functions socially established breeding and care taking it therefore by unable to fight. Thus, the feminine aspects are always interpreted as physical frailty, opposed to the value of rusticity, central military profession, to withstand adverse physical conditions and materials, which is perceived as a strictly male attribute.

Keywords: Naval Power. Strategy. Seapower. 
RBED, v. 2, no 1 , jan./jun. 2015

\section{REFERÊNCIAS}

Bourdieu, P. (2011) A distinção: crítica social do julgamento. Porto Alegre: Rio de Janeiro: Zook.

Butler, J. (2003) Problemas de gênero. São Paulo: Civilização Brasileira.

Cavedon, N. R. (2012) “Gênero, trabalho e morte violenta." In: Freitas M. E.; Dantas, M. (Orgs). Diversidade Sexual e Trabalho. São Paulo: Cengcage, Learning.

Da Matta, R. (1988) A casa e a rua. Rio de Janeiro: Guanabara Koogan.

Dantas, M. (Org) (2012) Diversidade sexual e trabalho. São Paulo: Cengcage, Learning.

Foucalt, M. (1988) História da Sexualidade: a vontade de saber. Rio de Janeiro: Graal.

Goffmann, E. (2001) Conventos, manicômios e prisões. São Paulo: Editora Perspectiva.

Melo, M. C. de O. L. (2012) "Mulheres gerentes entre o empoderamento e o teto de vidro.” In: Freitas M. E.; Dantas, M. (Orgs). Diversidade Sexual e Trabalho. São Paulo: Cengcage, Learning.

Miranda, A. L. N. M. (2013) Doutrina Militar Terrestre em revista. Ano 001. Edição 001.

Nogueira, C. M. (2004) A feminização do mundo do trabalho: entre a emancipação e a precarização. São Paulo: Autores associados.

Soares, B. M.; Musumeci, L. (2005) Mulheres policiais: presença feminina na polícia militar do Rio de Janeiro. Rio de Janeiro: Civilização Brasileira.

Takahashi, Emília. (2002) Homens e Mulheres em campo: um estudo sobre a formação da identidade militar. Campinas: Universidade Estadual de Campinas, Faculdade de Educação. Tese de doutorado, Programa de Pós-Graduação em Educação.

Visacro, A. (2009) Guerra irregular: terrorismo, guerrilha e movimentos de resistência ao longo da história. São Paulo: contexto. 


\section{Anexo A - Roteiro das Entrevistas}

Entrevistas realizadas com 25 instrutores militares de um estabelecimento de ensino subordinado ao Departamento de Educação e Cultura do Exército Brasileiro (DECEx), ao longo do ano de 2012.

1- Qual a sua patente, arma ou serviço?

2- Qual a sua patente?

3- Qual foi a sua trajetória profissional no EB? Onde serviu?

4- Indique uma personalidade pública de homem que seja admirável. Justifique a sua resposta.

5- Indique uma personalidade pública de mulher que seja admirável. Justifique a sua resposta.

6- Quando entrou em contato com mulheres no Exército ou em outras Forças Armadas e Auxiliares?

7- O que achou da atuação profissional, de caráter técnico, das mulheres, no EB?

8- O que acha de um filho seu ser militar do EB? Em caso positivo, o senhor prefere que seja técnico ou da linha bélica?

9- Prefere comandar ou ser comandado?

10- Analise esta história: "Na OMX, em região de risco, com desova constante de cadáveres, o Cmt, o Cel Peixoto retirou as mulheres da escala de serviço. Como avalia esta atitude do Cmt?"

11- Na Missão de Paz, no País Y, foram enviadas mulheres militares ao um hospital, com o intuito de realizar atividades com as crianças, vestindo fantasias diversas. Como considera essa forma de atuação do segmento feminino na Força Terrestre?

12- Se tivesse um filho, com quantos anos ele deveria começar a sua vida sexual?

13- O que o senhor acha desta frase: "As mulheres são mais dotadas para as atividades relacionadas ao cuidado e orientação dos filhos do que os homens."

14- Se tivesse uma filha, com quantos anos ela deveria começar a sua vida sexual?

15- Descreva a apresentação pessoal de um homem bem fardado.

16- Comente esta história: "Maria Costa é casada e tem dois filhos, de seis e oito anos. É advogada e trabalha em uma firma de renome. Trabalha 10 horas por dia.”

17- Descreva a apresentação pessoal de uma mulher bem fardada.

18- Comente esta história: "Paulo e Joana são casados há 10 anos e têm dois filhos. Joana é contadora e ganha 13 salários mínimos. Paulo é professor e ganha cinco salários mínimos".

19- Comente esta frase: "As mulheres são mais dotadas para os serviços domésticos do que os homens."

20- Depois dos 16 anos, quem decide sobre o aborto de uma criança...

21- Como deve ser o TFM de homens e mulheres, realizado durante o curso de linha bélica, no EB?

22- Como devem ser as atividades de campanha, para homens e mulheres, realizadas durante o curso de formação de militares da linha bélica, no EB?

23- De que forma deve ocorrer o ingresso da mulher na linha bélica quanto aos prazos e limites?

Recebido em: 24/04/2015. Aprovado em: 10/09/2015. 